\title{
Risk occurrence measures for dangerous goods goods transport on a road network
}

\author{
F. Russo \& C. Rindone \\ DIIES - Dipartimento di ingegneria dell'Informazione, \\ delle Infrastrutture e dell'Energia Sostenibile, \\ Università degli Studi Mediterranea di Reggio Calabria, Italy
}

\begin{abstract}
The purpose of this paper is to analyze some measures of risk occurrence relative to Dangerous Goods Transport (DGT) in the context of Transportation Risk Analysis (TRA). An index is proposed starting from the international classification of DGT and uses some specific parameters to weight the distances traveled by DGT.
\end{abstract}

Keywords: dangerous goods, road accident, risk analysis, occurrence, performance.

\section{Introduction}

Efficient freight transportation system supports the economic sustainability of a territory, but this activity could produce negative impacts on environmental and societal sustainability. Ex ante assessment of the impacts generated by freight transportation cannot be separated by the use of simulation models [1-3]. For some categories of goods, such as dangerous goods, trade off among impacts can be relevant. Dangerous goods are substances and products which need to associate a significant risk to people and the environment in a surrounding area.

In a compact formulation, risk has three components: occurrence, vulnerability and exposure [4]. The occurrence of vehicle accident during travelling dangerous goods is generally low, but the vulnerability and exposure can be very high, then the occurrence plays an important role in the transportation risk analysis. Vulnerability can be measured applying methodologies derived from industrial risk analysis. Exposure can be measured with methods of transport systems engineering [5, 6]. A possible planning 
activity to reduce exposure is evacuation [7]. A state of the art on models to simulate road evacuation is presented in [8].

In this paper, occurrence component is focused. To define a simplified measure of occurrence it needs to introduce the main elements of the general framework of Transportation Risk Analysis, then the international agreements that regulate the transport of dangerous goods, and - from another side - the formulation of road accidents probability.

TRA derives from Quantitative Risk Analysis (QRA) that has been developed for fixed plants [9]. A lot of software to support TRA relative to dangerous goods has been developed; we recall the main widespread European Decision Support System (DSS) that combines in a different way the elements previously introduced: TRAT-GIS [10]; QRAM [11, 12]; ARIPAR-GIS [13]; EHHRA-GIS [14].

The DSS considered use the complete TRA methodology, asking the knowledge of a large number of attributes and parameters to calculate the risk. There are other methods defined expeditious methods that give the risk using a low number of attributes and parameters furnishing only a first level of risk. Just considering only methods developed and applied in EU countries, we can recall: Shortcut method [15]; quantitative risk assessment approaches adopted in some European Countries (Italy, United Kingdom, France, the Walloon Region of Belgium and the Netherland) $[12,16]$.

International agreements regulate transport activities for each land mode [17]: ADR for road transport; RID for rail transport; ADN for inland waterways. These agreements indicate a list of dangerous goods, defining the requirements to senders, carriers, vehicle owners, drivers and recipients. Rules can be effective if they are also enforced. Regulations are updated on a regular cycle to incorporate revisions made by the UN recommendations.

In literature, different models to estimate the probability of a road accident occurring are proposed. A state of the art of these models is presented in recent literature [18-20].

The number of accidents (A), in a temporal period (day, month, year), is estimated by means of models using a function that depend on independent attributes $\left(\mathrm{K}_{\mathrm{i}}\right)$ and parameters $\left(\alpha_{\mathrm{i}}\right)$ :

$$
\mathrm{A}=f\left(\mathrm{~K}_{\mathrm{i}}, \alpha_{\mathrm{i}}\right)
$$

A great part of quantitative models, available in literature, adopt link or network flows as independent attributes.

Some aggregate accident models consider flows expressed in terms of distances traveled by road vehicles. For instance Berhanu [21], in order to estimate the annual number of road accidents (I) proposes the function:

$$
\mathrm{I}=\mathrm{K}_{1} \alpha_{1} \exp \left(-\alpha_{2} \mathrm{~K}_{2}+\alpha_{3}\right)
$$

where:

$\mathrm{K}_{1} \quad$ is the annual number of distances traveled by road vehicles (veic*km);

$\mathrm{K}_{2} \quad$ is the number of the road lanes (number);

$\alpha_{1}, \alpha_{1}, \alpha_{1} \quad$ are the calibrated parameters. 
The accident probability is then a function of the link flow. We can assume that similar dependency exists if we consider only the flows of dangerous goods.

In this paper an analysis of DGT in Europe is recalled using the general estimates of Eurostat. The analysis is focused on 15 member (EU15) countries in the European Union prior to the accession of ten candidate countries on 2004. Attention is given to occurrences related to accidents involving dangerous goods. To analyze an occurrence, an aggregate index, based on international classification of dangerous goods is proposed. This is a first attempt to homogenize dangerous goods of different classes.

The paper, after this introduction, has two sections: in section 2 an analysis of quantity of DGT at European level is presented; in section 3 an aggregate method to estimate the occurrence is proposed with an application at European scale.

\section{Dangerous goods transport quantities measures}

Available European statistical data on DGT are collected in EUROSTAT database [22]. The used information is elaborated leaving from this database. Referring to EU15, total DGT amounts to $13809 * 10^{6} \mathrm{t}$ [tonnes] and $1682996 * 10^{6}$ tkm [tonnes*km] (Tab. 1).

In the same context, DGT, measured in terms of tkm, represents $7.6 \%$ of total transport of goods; this percentage is $13.5 \%$ for rail, $5.2 \%$ for road and $20 \%$ for inland waterways.

Table 1: $\quad$ Transport of goods and DGT in Europe in 2011 (EU15).

\begin{tabular}{|c|c|c|c|c|c|}
\hline & \multicolumn{2}{|r|}{ Total goods } & \multicolumn{3}{|c|}{ Dangerous Good Transport (DGT) } \\
\hline & $\begin{array}{c}\text { v.a. } \\
\left(10^{6} \mathrm{tkm}\right)\end{array}$ & $\begin{array}{c}\text { Modal } \\
\text { share } \\
(\%)\end{array}$ & $\begin{array}{c}\text { v.a. } \\
\left(10^{6} \mathrm{tkm}\right)\end{array}$ & $\begin{array}{c}\text { Modal } \\
\text { share } \\
(\%)\end{array}$ & $\begin{array}{c}\text { Incidence } \\
\text { total goods } \\
(\%)\end{array}$ \\
\hline Rail & 264083 & $15.7 \%$ & 35770 & $28.14 \%$ & $13.5 \%$ \\
\hline Road & 1296857 & $77.1 \%$ & 66955 & $52.66 \%$ & $5.2 \%$ \\
\hline $\begin{array}{l}\text { Inland } \\
\text { waterways }\end{array}$ & 122056 & $7.3 \%$ & 24411 & $19.20 \%$ & $20.0 \%$ \\
\hline Total & 1682996 & $100.0 \%$ & 127464 & $100.0 \%$ & $7.6 \%$ \\
\hline
\end{tabular}

Source: elaboration from EC [22].

International classifications relative to DGT are based on the orange book published by United Nations [23]. The orange book classes are defined according to the hazard or the most predominant of the hazards they present. We define $\mathbf{u}$ the vector of ADR classes and divisions [17], (tab. 2) with dimension $\operatorname{dim}(\mathbf{u})=13$.

According to ADR, transport units carrying dangerous goods shall display two rectangular orange-coloured plates conforming to ADR 5.3.2.2.1 [17], set in a vertical plane. These plates have to indicate:

- hazard identification number, Kemler code, positioned in the high part of the panel; this code give information about the hazards associated to the material; 
and

- the UN number prescribed positioned in the low part of the panel.

We define $\mathbf{v}$ the vector of Kemler code and $\mathbf{z}$ the vector of UN number [17], and define $\operatorname{dim}(\mathbf{v})$ and $\operatorname{dim}(\mathbf{z})$ the relative dimensions.

With this position we can define $f_{u j}, f_{v j}, f_{z j}$ the flow in the link $j$ measured in vehicle (hour/day/week/month/year) classified for $u, v$ and $z$.

Considering the reference normative we have that [17]: $\operatorname{dim}(\mathbf{v})=100 ; \operatorname{dim}$ $(\mathbf{z})=3496$.

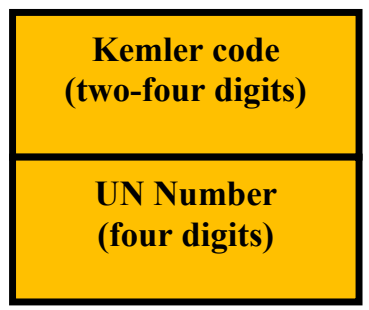

Figure 1: $\quad$ Orange-coloured plate according to ADR [17].

In the same way we can define the variable relative to the quantities travelling in each link $\mathrm{j}$, of length equal to $\mathrm{d}_{\mathrm{j}}: \mathrm{q}_{\mathrm{j}}{ }^{\mathrm{y}} ; \mathrm{q}_{\mathrm{u}, \mathrm{j}}{ }^{\mathrm{y}} ; \mathrm{q}_{\mathrm{v}, \mathrm{j}}{ }^{\mathrm{y}} ; \mathrm{q}_{\mathrm{z}, \mathrm{j}}{ }^{\mathrm{y}}$ where y refers to yearly quantities travelling. In the Tab. 2 DGT by road quantities and ADR class expressed in tkm are reported. Obtained by calculating $\sum_{j \in n e t} \mathrm{q}_{\mathrm{u}, \mathrm{j}}{ }^{\mathrm{y}} \mathrm{d}_{\mathrm{j}}$ extended to all links of the EU15 road networks. In EU15, referring to 2011, flammable liquids (class 3), gases (class 2) and corrosive substances (class 8) constitute the most part of total quantities $(83 \%)$. Total flammable liquids (class 3 ) are the largest percentage of DGT $(59 \%)$. Gas is the second percentage transported (14\%); corrosive substances constitute the third (10\%).

Table 2: $\quad$ DGT by road and ADR class (tkm).

\begin{tabular}{llrr}
\hline ADR class & tkm & \\
$(u)$ & & $\left(\sum_{\mathrm{j} \in \mathrm{net}} \mathrm{q}_{\mathrm{u}, \mathrm{j}} \mathrm{y}_{\mathrm{j}}\right)$ & $\%$ \\
\hline 1 & Explosives & 387 & $0.6 \%$ \\
2 & Gases & 9289 & $13.9 \%$ \\
3 & Flammable liquids & 39468 & $58.9 \%$ \\
4.1. & Flammable solids & 757 & $1.1 \%$ \\
4.2. & Substances liable to spontaneous combustion & 1824 & $2.7 \%$ \\
4.3. & Substances which in contact with water emit & 25 & $0.0 \%$ \\
5.1. & Olammable gases & 2347 & $3.5 \%$ \\
5.2. & Organic peroxides & 52 & $0.1 \%$ \\
6.1. & Toxic substances & 1209 & $1.8 \%$ \\
6.2. & Infectious substances & 376 & $0.6 \%$ \\
7 & Radioactive material & 78 & $0.1 \%$ \\
8 & Corrosive substances & 6716 & $10.0 \%$ \\
9 & Miscellaneous dangerous substances & 4427 & $6.6 \%$ \\
\hline & TOTAL & 66955 & $100.0 \%$ \\
\hline
\end{tabular}

Source: elaboration from EC [22]. 


\section{An estimation of the occurrence}

\subsection{The used classification}

$\mathrm{UN}(z)$ and ADR $(u)$ classifications do not allow us to weigh directly DGT quantities in relation to hazard of carried substances.

An aggregate classification, that allows unique definition of an aggregate hazard index, is not available in literature.

To obtain a first level of weight relative to the occurrence of difference class of dangerous goods, it needs to introduce other classifications adopted:

- Emergency Response Guidebook (ERG) classification adopted from US DoT and Transport Canada [24];

- SEVESO classification relative to Italian law that regulate relevant accidents (D. Lgs 334/1999) [25];

- ADR classification relative to transport category [17].

In this work transport category classification reported in ADR is now considered. In ADR manual, each dangerous good is identified by a proper shipping name, an UN identification number (vector $\mathbf{z}$ previously defined), an ADR class (vector $\mathbf{u}$ ) and a packing group number that indicated the level of danger: packing group I, high danger; packing group II, medium danger; packing group III, low danger according to their inherent potential to affect adversely humans, the environment, or property. This classification is based on a number of factors, such as vapor pressure, flash point, toxicity, and corrosivity and defined in the UN Recommendations and transport agreements [17].

In the section ADR 1.1.3.6 are reported the exemptions related to quantities carried per transport unit. In particular the table reported in section 1.1.3.6.3 indicate the transport category to assign at DGT by road according to packing group. For each transport category a maximum total quantity per transport unit is indicated (Tab. 3). We define $\mathbf{r}$ the vector of transport categories.

In section ADR 1.1.3.6.4, at each transport category, except for transport category 0 , a multiplier coefficient is associated to verify load size limits in the case of a mixed load on single truck. In particular the limit quantities of substances for each category are reported in Tab. 3 .

Table 3: $\quad$ ADR transport category.

\begin{tabular}{|c|c|c|c|}
\hline $\begin{array}{l}\text { Transport } \\
\text { category } \\
\text { (r) }\end{array}$ & $\begin{array}{l}\text { Packing } \\
\text { Group }\end{array}$ & $\begin{array}{l}\text { Maximum } \\
\text { total quantity } \\
\text { per transport } \\
\text { unit } \\
\left(q_{\text {max }}^{r}\right) \\
\end{array}$ & $\begin{array}{l}\text { Multiplier } \\
\text { (packing) }\end{array}$ \\
\hline 0 & Some explosive and relative uncleaned & 0 & $\infty$ \\
\hline 1 & Packing Group I & 20 & $20-50$ \\
\hline 2 & Packing Group II & 333 & 3 \\
\hline 3 & Packing Group III & 1000 & 1 \\
\hline 4 & Uncleaned packaging except transport & Unlimited & 1 \\
\hline
\end{tabular}

Source: UNECE [17]. 
To use operatively the multipliers it needs to introduce a finite parameter for the category 0 . Different trends have been analysed. Polynomial trend is, preliminary, selected from which a multiplier to associate at transport category 0 is calculated and it is near to 110 (Fig. 2).

We translate the approach of homogenizing the different load of DGT in a single vehicle into different quantities of DGT in the network.

In this way we assume that in a generic road link the relative weight can be obtained using the multipliers of transport category. We can use the vector $\mathbf{r}$ of transport categories of 5 elements and we introduce the vector c of equal dimension where each element contains the multiplier. We note that for each element of $\mathbf{z}$ a multiplier belonging to $\mathbf{c}$ is defined, then we can introduce a vector $\mathbf{m}$ of dimension $\operatorname{dim}(\mathbf{m})=\operatorname{dim}(\mathbf{z})$, that gives for each element of $\mathbf{z}$ the correspondent multiplier of $\mathbf{c}$.

We can define a capacity limit for each road link extending the approach for single truck.

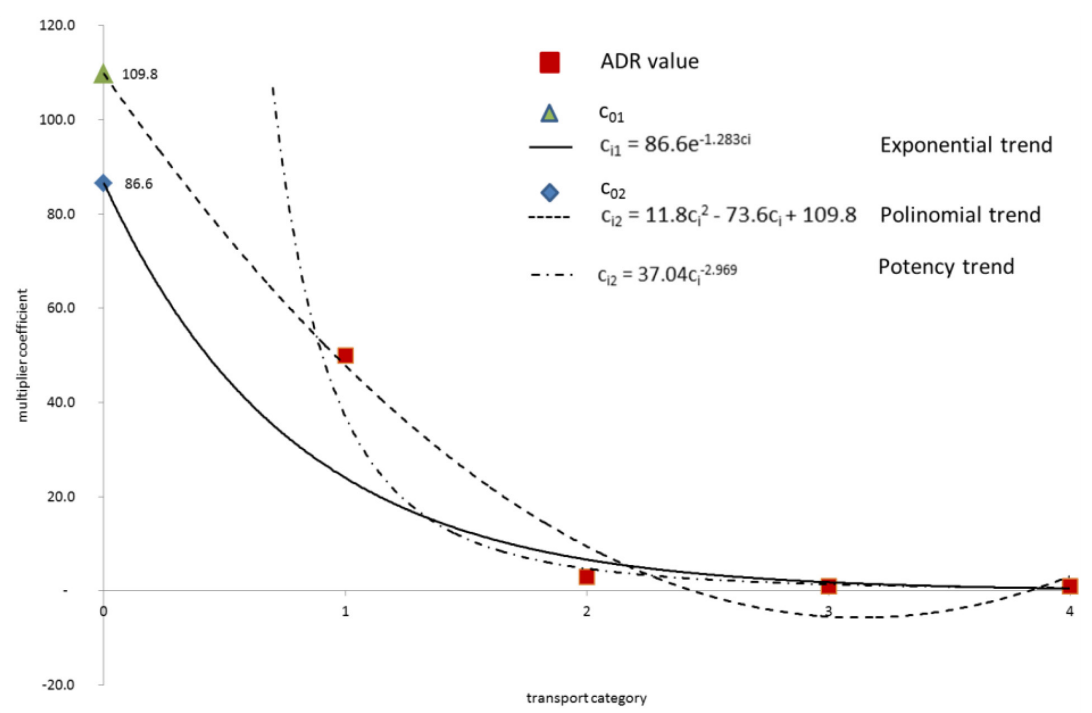

Figure 2: $\quad$ Inference of multiplier for transport category.

\subsection{An occurrence index by transport category}

Using the transport category introduced in previous sections expressed by vector $\mathbf{z}$, the packing multiplier expressed by vector $\mathbf{c}$, and the weights vector $\mathbf{m}$, a possible specification of risk occurrence index can be proposed. It needs to introduce the hypothesis that, for each class $z$, there is a linear dependence between $f_{z, j}$ and $q_{z, j}$ or that there is only one type of vehicle.

Under these hypotheses we can express the occurrence index in terms of quantity instead of flow in the function (2). In this case the occurrence can be evaluated introducing a variable $\mathrm{o}_{z, \mathrm{j}}$ representing the occurrence relative to DGT $\mathrm{z}$ in the link $\mathrm{j}$ : 


$$
\mathrm{o}_{\mathrm{z}, \mathrm{j}}=\mathrm{q}_{\mathrm{z}, \mathrm{j}} * \mathrm{~d}_{\mathrm{j}} * \mathrm{~m}_{\mathrm{z}}
$$

on the complete network

$$
\mathrm{O}_{\mathrm{z}, \text { net }}=\Sigma_{\mathrm{j} \in \text { net }} \mathrm{O}_{\mathrm{z}, \mathrm{j}}
$$

where:

$\mathrm{q}_{\mathrm{z}, \mathrm{j}}$ : $\quad$ is the annual quantity of dangerous goods belong to $z$ class expressed in terms of $t$;

$\mathrm{d}_{\mathrm{j}}$ : $\quad$ is the length of the link $\mathrm{j}(\mathrm{km})$;

$\mathrm{m}_{\mathrm{z}}$ : is the multiplier assigned to transport category $z$ of dangerous goods.

If DGT by road quantities are available for single UN number $(z)$, this number has a weight defined by the multiplier $\mathrm{m}$ and the occurrence network index can be calculated. Unfortunately the quantities relative to each carried goods is actually not available following UN number $(z)$.

Data on DGT by road quantities are available in official sources in terms of ADR class (Tab. 2), vector u. At each ADR class can correspond different packing groups, then different transport categories and then different multiplier coefficients.

It is useful to introduce the following vectors and matrices:

$\mathbf{t}$

is the vector of DGT quantities by ADR class of dimension dim $(\mathbf{t})=\operatorname{dim}(\mathbf{u})$; each element $t_{\mathrm{u}}$ represents the road DGT quantity $\left(\sum_{\mathrm{j} \in \text { net }} \mathrm{q}_{\mathrm{u}, \mathrm{j}}^{\mathrm{y}} \mathrm{d}_{\mathrm{j}}\right)$ relative to each ADR class; the elements of this vector can be calculated by model or can be revealed by ad hoc survey;

$\mathbf{A}=\operatorname{Diag}(\mathbf{t}) \quad$ is a diagonal matrix of dimensions $\operatorname{dim}(\mathbf{u} \times \mathbf{u})$; in the diagonal DGT quantities by ADR class present in vector $\mathbf{t}$ are reported, the other elements of the matrix are equal to 0 ;

c is the vector of multiplier coefficients relative to each transport category;

H is an incidence matrix ADR class $\times$ transport category; this matrix has dimensions $\operatorname{dim}(\mathbf{t} \times \mathbf{r})$; the generic element $h_{u, r}$ of the matrix is the percentage of DGT quantities relative to $u$ ADR class, and $r$ transport category.

In Tab. 4 is presented the incidence matrix $\mathbf{H}$ with rows equal to ADR classes $(u)$ and columns equal to transport categories $(r)$; in each element is posed the element $\mathrm{X}$ to indicate that the element is different from 0 ; the other elements have zero value.

Leaving from the vectors and matrices defined, an occurrence index vector $\mathbf{0}_{\mathbf{u}, \text { net }}$ can be obtained with the follow formulation:

$$
\mathbf{o}_{\mathbf{u}, \text { net }}=\mathbf{A} * \mathbf{H} * \mathbf{c}
$$


Table 4: $\quad$ Multiplier coefficient for each ADR class.

\begin{tabular}{llccccc}
\hline & & \multicolumn{5}{c}{ Transport category } \\
\hline ADR class $(u)$ & 4 & 3 & 2 & 1 & 0 \\
\hline 1 & Explosives & $\mathrm{X}$ & 0 & $\mathrm{X}$ & $\mathrm{X}$ & $\mathrm{X}$ \\
2 & Gases & $\mathrm{X}$ & $\mathrm{X}$ & $\mathrm{X}$ & $\mathrm{X}$ & 0 \\
3 & Flammable liquids & 0 & $\mathrm{X}$ & $\mathrm{X}$ & $\mathrm{X}$ & $\mathrm{X}$ \\
4.1. & Flammable solids & 0 & $\mathrm{X}$ & $\mathrm{X}$ & $\mathrm{X}$ & 0 \\
4.2. & Substances liable to spontaneous combustion & 0 & $\mathrm{X}$ & $\mathrm{X}$ & $\mathrm{X}$ & $\mathrm{X}$ \\
4.3. & Substances which in contact with water emit flammable & 0 & 0 & $\mathrm{X}$ & $\mathrm{X}$ & $\mathrm{X}$ \\
5.1. & Oxidising substances & 0 & $\mathrm{X}$ & $\mathrm{X}$ & $\mathrm{X}$ & $\mathrm{X}$ \\
5.2. & Organic peroxides & 0 & 0 & $\mathrm{X}$ & $\mathrm{X}$ & 0 \\
6.1. & Toxic substances & 0 & 0 & $\mathrm{X}$ & $\mathrm{X}$ & $\mathrm{X}$ \\
6.2. & Infectious substances & 0 & 0 & $\mathrm{X}$ & $\mathrm{X}$ & 0 \\
7 & Radioactive material & 0 & 0 & 0 & 0 & $\mathrm{X}$ \\
8 & Corrosive substances & 0 & $\mathrm{X}$ & $\mathrm{X}$ & $\mathrm{X}$ & $\mathrm{X}$ \\
9 & Miscellaneous dangerous substances & $\mathrm{X}$ & $\mathrm{X}$ & $\mathrm{X}$ & 0 & $\mathrm{X}$ \\
\hline
\end{tabular}

\subsection{An application at European scale}

The percentages of the $\mathbf{H}$ matrix are not available. For this reason we introduce some hypotheses of sensitivity and calculate the relative $\mathbf{H}$ matrices. The considered hypotheses are:

- $\mathbf{H}_{\min }$ matrix, obtained hypothesizing that total DGT quantities of each ADR class belong to transport category with minimum multiplier coefficient; for each ADR class, each raw has value equal to 0, except for the category with minimum multiplier coefficient that has value equal to 1 ;

- $\mathbf{H}_{\text {med }}$ matrix, obtained hypothesizing that DGT quantities of each ADR class are equally distributed among transport categories;

- $\mathbf{H}_{\max }$ matrix, obtained hypothesizing that total DGT quantities of each ADR class belong to transport category with maximum multiplier coefficient; for each ADR class, each raw has value equal to 0 , except for the category with maximum multiplier coefficient that has value equal to 1 .

To calculate occurrence index, starting from available official data, the formulation (5) is applied introducing the $\mathbf{H}$ matrices defined; the quantities reported in Tab. 5 have been calculated.

From the results, some preliminary considerations can be proposed. At European level, flammable liquids (class 3 ) and gases (class 2) have not the same incidence evaluated using only the quantities: class 3 moves from $50.1 \%$ to $66.4 \%$; class 3 moves from $5.2 \%$ to $13.9 \%$.

It needs to highlights the role of radioactive material, that have very low percentage in tkm, but that increases sensitively considering the multiplier, obtaining the third percentage in terms of occurrence index in the case of $\mathrm{o}_{\min }$. 


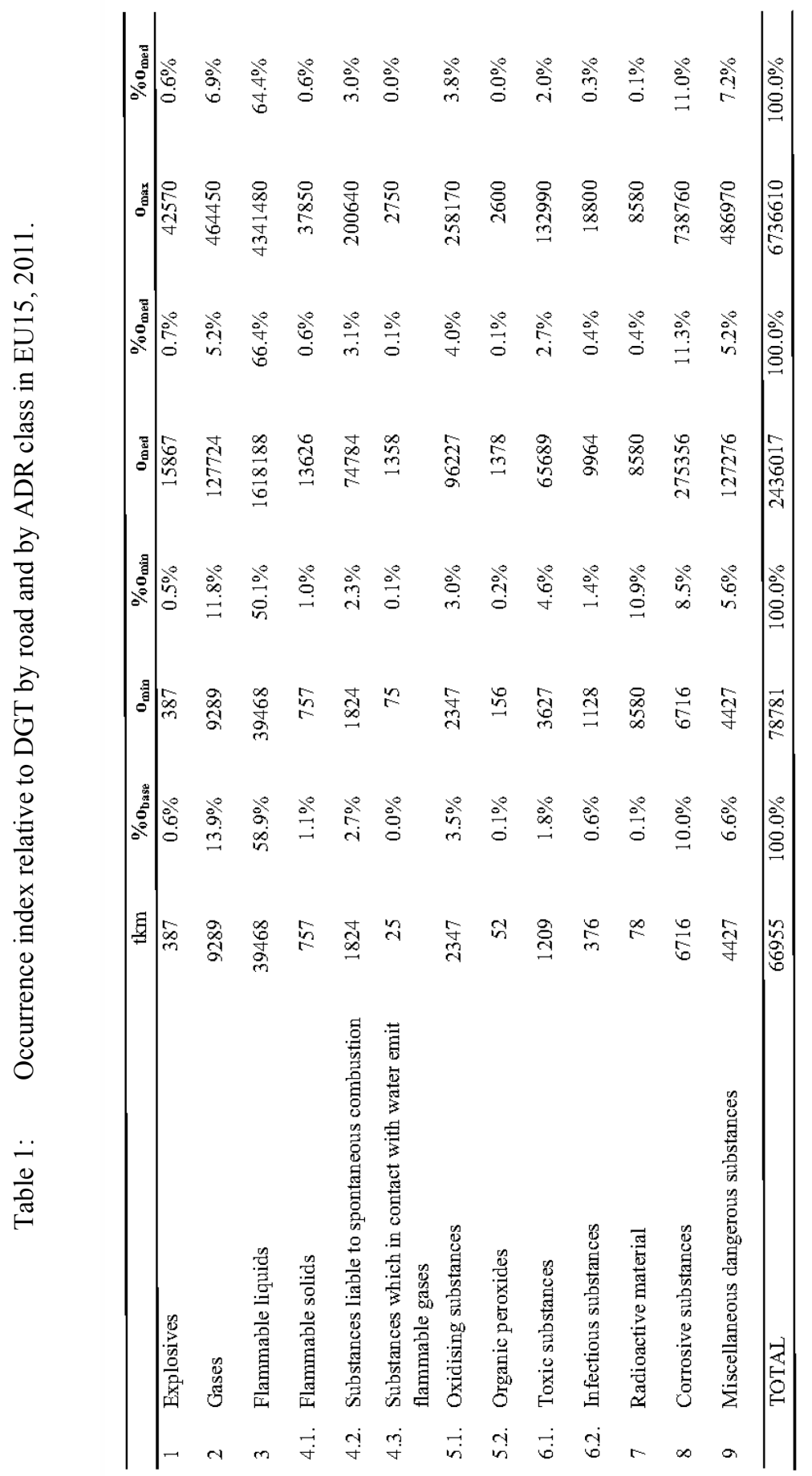




\section{References}

[1] Russo F. and Cartenì, A., A distribution regional freight demand model, Advances in Transport, Vol. 16, pp. 275-285, 2004.

[2] Russo, F., Musolino, G. and Trecozzi, M.R., A system of models for the assessment of an urban distribution center in a city logistic plan, WIT Transactions on the Built Environment, Vol. 130, pp. 799-810, 2013.

[3] Polimeni, A. and Vitetta, A., A comparison of vehicle routing approaches with link costs variability: An application for a city logistic plan, WIT Transactions on the Built Environment, Vol. 130, pp. 823-834, 2013.

[4] Russo F. and Vitetta A., Risk evaluation in a transportation system. International Journal of Sustainable Development and Planning, 1 (2), pp. 170-191, 2006.

[5] Russo F. and Vitetta A., Safety of users in road evacuation: General methodology and main results. WIT Transactions on the Built Environment, Vol. 96, pp. 763-772, 2007.

[6] Russo F. and Vitetta A., A methodology for evacuation design for urban areas: Theoretical aspects and experimentation, Summer Computer Simulation Conference 2008, SCSC 2008, Part of the 2008 Summer Simulation Multiconference, SummerSim 2008, pp. 538-551, 2008.

[7] Russo, F., Rindone, C., Planning in road evacuation: Classification of exogenous activities, WIT Transactions on the Built Environment Vol. 116, pp. 639-651, 2011.

[8] De Maio, M.L., Musolino, G. \& Vitetta, A., Traffic assignment models in road evacuation, WIT Transactions on Ecology and the Environment Vol. 155 , pp. 1041-1051, 2011.

[9] CCPS. Center for Chemical Process Safety, Guidelines for chemical transportation risk analysis, American Institute of Chemical Engineers, New York, 1995.

[10] Milazzo, M.F., Lisi, R., Maschio, G., Antonioni G. \& Spadoni G., A study of land transport of dangerous substances in Eastern Sicily, Journal of Loss Prevention in the Process Industries, Vol. 15, pp. 347-356, Elsevier, 2010.

[11] Cassini, P., Overview of the DG-QRAM, Proceedings of International Seminar Quantitative risk assessment model for dangerous goods transport through road tunnels, INERIS, OECD, Paris (France), 26 January 2010.

[12] Gooijer, L., Cornil N. and Lenoble C.L., An international comparison of four quantitative risk assessment approaches, RIVM Report 620552001/2011, http:/www.rivm.nl/bibliotheek/rapporten/620552001.pdf (last access, May 2013), 2011.

[13] Spadoni G., Egidi D. and Contini S., Through ARIPAR-GIS the quantified area risk analysis supports land-use planning activities, Journal of Hazardous Materials, Vol. 71, pp. 423-437, Elsevier, 2000.

[14] Bagli S. and Spadoni G., A multimedia, multiple pathway exposure and risk assessment using EHHRA-GIS: a real case of contamination due to an industrial facility, Management Information Systems, pp. 115-124, 2000. 
[15] APAT, ARPAT, Metodo Shortcut per la valutazione delle conseguenze incidentali. Convention APAT, ARPAT, 2001. User'manual, ISBN 88-4480159-0, 2005.

[16] Italian Government, DPCM 25 Febraury 2005, Linee Guida per la predisposizione del piano d'emergenza esterna di cui all'articolo 20, comma 4, del decreto legislativo 17 agosto 1999, n. 334. (GU n. 62 del 163-2005 - Suppl. Ordinario n.40), 2005.

[17] UNECE. United Nations Economic Commission for Europe. Dangerous Goods, http://www.unece.org/trans/danger/danger.html (last access, April, 2013), 2013.

[18] Delfino G., Rindone C., Russo F., Quattrone A. and Vitetta A., ITS for monitoring and estimating road accident probability for dangerous goods transport, ETC, Proceedings of the European Transport Conference, AET GBR, 2008.

[19] Marcianò A. and Vitetta A., An individual risk model in the case of a road accident to support the decision process in planning, WIT Transactions on Information and Communication Technologies Vol. 43, PART I, pp. PI481-PI493, 2010.

[20] Marcianò F.A. and Vitetta A., Risk analysis in road safety: an individual risk model for drivers and pedestrians to support decision planning processes, International Journal of Safety and Security Engineering, Vol. 1, No. 3 pp. 265-282, 2011.

[21] Berhanu G., Models relating traffic safety with road environment and traffic flows on arterial roads in Addis Ababa. Accident Analysis and Prevention, Vol. 36, pp 697-704, 2004.

[22] EC. European Commission. Eurostat database. http://epp.eurostat.ec. europa.eu/portal/page/portal/statistics/search_database (last access, May 2013), 2013.

[23] UN. United Nations. UN Recommendations on the Transport of Dangerous Goods - Model Regulations, Orange Book, Seventeenth revised edition, Copyright (C) United Nations, 2011, http://www.unece.org/trans/danger /publi/unrec/rev17/17files_e.html (last access, April 2013), 2013.

[24] US DoT. US Department of Transportation, Transport Canada, Emergency Response Guidebook (ERG), http://www.phmsa.dot.gov/staticfiles/PHMSA /DownloadableFiles/Files/Hazmat/ERG2012.pdf (last access, May 2013), 2013.

[25] Italian Government, Decreto Legislativo 17 agosto 1999, n. 334. Attuazione della direttiva 96/82/CE relativa al controllo dei pericoli di incidenti rilevanti connessi con determinate sostanze pericolose. (GU n.228 del 28-91999 - Suppl. Ordinario n. 177), 1999. 